\title{
Comparison of Infant Complication between Emergency and Caesarean Sections: A Meta-Analysis
}

\author{
Rahmi Padlilah, Ika Yulianti
}

Faculty of Health Sciences, Universitas Borneo Tarakan

\section{ABSTRACT}

Background: The World Health Organization (WHO) calls for all regions in the world not to have a caesarean section (SC) rate of more than 15\%. Globally, since 2003-2018, Emergency Caesarean Section (EmCS) and Elective Caesarean Section (ElCS) actions have continued to increase by $4 \%$ each year to $21 \%$. Previous studies report that EmCS increases the risk of complications in the fetus compared to ElCS. Based on the problem above, this study aims to analyze and compare complications experienced by the fetus in the process of Emergency Caesarean Section (EmCS) and Elective Caesarean Section (ElCS).

Subjects and Method: This was systematic review and meta-analysis study, which was conducted from July-August 2019. The data were obtained from PubMed, Science Direct, Web of Science, Springer Link, and Cochrane Database. The keywords were "elective cesarean section (ElCS) AND emergency cesarean section (EmCS)" AND "emergency cesarean section (EmCS) and fetal complication" AND "elective cesarean section (ECS) and fetal complication" AND "elective cesarean section (EmCS) AND fetal complication" (ElCS) AND emergency ce- sarean section (EmCS) AND fetal complication. Results: Emergency cesarean section increases the likelihood of neonatal death 4 times higher than the elective cesarean section and is statistically significant $(\mathrm{RR}=4.02 ; 95 \% \mathrm{CI}=$ 2.41 to 6.72). Emergency cesarean section can increase the likelihood of apgar score decrease 2 times higher than elective cesarean section and statistically significant $(\mathrm{RR}=2.07 ; 95 \% \mathrm{CI}=$ 1.03 to 4.15). Emergency cesarean section is 1.62 times higher than elective cesarean section and statistically significant $(\mathrm{OR}=1.62 ; 95 \% \mathrm{CI}=$ 1.19 to 2.20 ).

Conclusion: Emergency cesarean section can increase the likelihood of death, decrease Apgar score $<6$, and hypoxia in the fetus compared to elective cesarean section.

Keywords: emergency cesarean section, elective cesarean section, meta-analysis

\section{Correspondence:}

Ika Yulianti. Faculty of Health Science, Universitas Borneo Tarakan, North Kalimantan, Indonesia. Email: ikatamaevan@gmail.com. Mobile: $+628115440036$

\section{Cite this as:}

Padlilah R, Yulianti I (2020). Comparison of Infant Complication between Emergency and Caesarean Section: A Meta-Analysis. J Matern Child Health. 5(2): 200-205.

https://doi.org/10.26911/thejmch.2020.05.02.10

cc (i) (2) Journal of Maternal and Child Health is licensed under a Creative Commons EY NC SA Attribution-Non Commercial-Share Alike 4.0 International License.

\section{BACKGROUND}

Conventionally, cesarean section is classified as elective surgery or emergency surgery. Emergency caesarean section (EmCS) is performed in pregnancy where vaginal delivery is planned at first, but then there is an indication for caesarean delivery (Lucas et al, 2000). Meanwhile, elective caesarean section (ElCS) is a preferred or scheduled surgery, prearranged, most often arranged for medical indications that have developed before or during pregnancy, and ideally performed after 39 weeks of gestation (Yang and Sun, 2017).

World health organization (WHO) urges all regions in the world not to have Caesarean Section (SC) value more than $15 \%$, this is done to reduce the negative 
effects of SC actions. But globally since 2003-2018 caesarean section continues to increase by $4 \%$ every year to reach $21 \%$ (World Health Organization, 2015).

Previous studies have reported an increase in SC action that can increase labor costs, morbidity and mortality in the fetus. Common fetal complications are asphyxia, tachypnea, respiratory distress syndrome, sepsis, and soft tissue injuries (Vogel et al., 2015; Benzouina et al., 2016; Diana and Tipandjan, 2016).

The Congress of American Obstetrics and Gynecologists and policy makers reviewed various studies and found more incidences of sepsis, respiratory distress syndrome (RDS), hypoglycemia, the need to enter the NICU, and the need for hospitalization >4-5 days. (National Institute for Health and Care Excellence [NICE], 2011)

Based on the problem above, this study aims to analyze and compare the complications experienced by the fetus in the process of Emergency Caesarean Section (EmCS) and Elective Caesarean Section (ElCS).

\section{SUBJECTS AND METHOD}

\section{Study Design}

This study was a systematic review and meta-analysis, where the researcher studies and presents a summary of various specific medical reports (Biondi-Zoccai et al., 2011). Data were searched and processed from July-August 2019.

The data was sought from several indexing including: PubMed, Science Direct, Web of Science, Springer Link and Cochrane Database using search keywords "elective cesarean section (ElCS) and emer- gency cesarean section (EmCS)" and "emergency cesarean section (EmCS)" and fetal complication "and" elective cesarean section (ECS) and fetal complication "and" elective cesarean section (ElCS) and emergency cesarean section (EmCS) and fetal complication.

\section{Inclusion and Exclusion Criteria Inclusion Criteria}

The inclusion criteria were full paper randomized controlled trial articles, retrospective cohorts or prospective cohorts. Measures observed were elective cesarean section (ElCS) and emergency cesarean section (EmCS). Study subjects were women of reproductive age. The outcome observed was complications or fetal morbidity.

\section{Exclusion Criteria}

The study was conducted with a quasiexperimental, study protocol or pilot study. Published articles are in Arabic, Spanish, Chinese, French and Russian. Comparative measures are normal delivery, vacuum extraction or forceps extraction.

\section{Data Extraction}

The articles were collected and extracted using Preferred Reporting Items for Systematic Reviews and Meta-Analyses (PRISMA). RevMan 5 program was used for meta-analysis, analysis including random effects and intention to treat (ITT).

\section{RESULTS}

\section{Sample Characteristics}

A total of 58 articles were identified during the initial search of the entire database. After eliminating duplication and applying exclusion criteria, a total of 8 articles were further analyzed (Figure 1). 
Padlilah et al./ Comparison of Infant Complication between Emergency and Caesarean Section

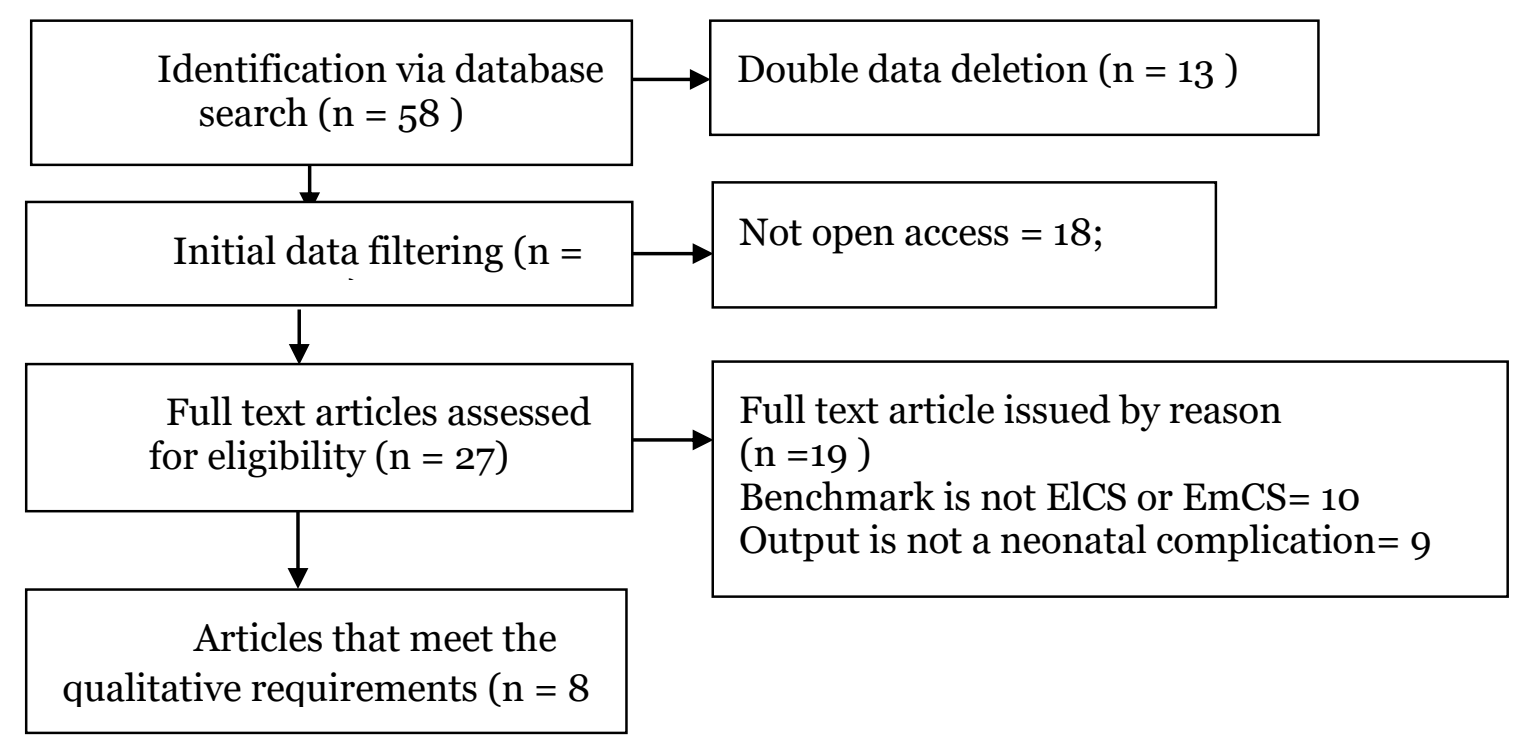

\section{Figure 1. PRIMSA Flow Diagram}

\section{Neonatal Death}

From Figure 2, it can be seen that the emergency cesarean section can increase the likelihood of neonatal death 4 times higher than the elective cesarean section and is statistically significant $(\mathrm{RR}=4.02 ; 95 \% \mathrm{CI}$ $=2.41$ to 6.72 ).

\section{Apgar Score $<6$}

Figure 3 showed that the emergency cesarean section could increase the likelihood of
Apgar score 2 times more likely than the elective cesarean section and is statistically significant $(\mathrm{RR}=2.07 ; 95 \% \mathrm{CI}=1.03$ to 4.15).

\section{Hypoxia}

Figure 4 showed that the incidence of hypoxia in emergency cesarean section was 1.62 times more likely than the elective cesarean section and statistically significant $(\mathrm{OR}=1.62 ; 95 \% \mathrm{CI}=1.19$ to 2.20 ).

\begin{tabular}{|c|c|c|c|c|c|}
\hline \multirow[b]{2}{*}{ Study or Subgroup } & \multicolumn{2}{|c|}{ EmCS } & \multicolumn{2}{|c|}{ EICS } & \multirow[b]{2}{*}{ Weight } \\
\hline & Events & Total & Events & Total & \\
\hline Benzouina et al 2016 & 6 & 446 & 0 & 142 & $3.0 \%$ \\
\hline Chongsuvivatwong et al 2010 & 54 & 4328 & 8 & 3062 & $26.2 \%$ \\
\hline Nahid et al 2000 & 9 & 97 & 2 & 94 & $9.7 \%$ \\
\hline Najam et al 2013 & 18 & 130 & 2 & 47 & $10.6 \%$ \\
\hline Thakur et al 2015 & 279 & 2521 & 12 & 696 & $33.6 \%$ \\
\hline Valsa and Diana 2016 & 16 & 151 & 4 & 50 & $16.9 \%$ \\
\hline Total $(95 \% \mathrm{Cl})$ & & 7673 & & 4091 & $100.0 \%$ \\
\hline Total events & 382 & & 28 & & \\
\hline $\begin{array}{l}\text { Heterogeneity: } \operatorname{Tau}^{2}=0.12 ; \mathrm{Ch} \\
\text { Test for overall effect: } Z=5.32\end{array}$ & $\begin{array}{l}7.19, \mathrm{~d} \\
=0.0000\end{array}$ & $\begin{array}{l}f=5(f \\
01)\end{array}$ & .21); 1 & -30 & \\
\hline
\end{tabular}

Risk Ratio $\quad$ Risk Ratio , Random, $95 \% \mathrm{Cl}$ $4.16[0.24,73.37]$ $4.78[2.28,10.02]$ $4.36[0.97,19.66]$ $3.25[0.78,13.49]$ $6.42[3.62,11.37]$

$1.32[0.46,3.78]$ $4.02[2.41,6.72]$

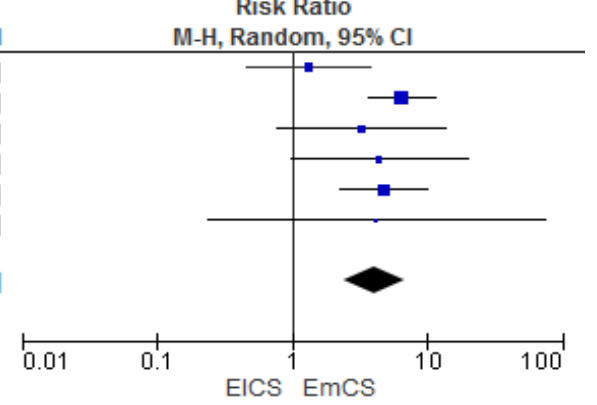

Figure 2. Forest plot neonatal death 
Padlilah et al./ Comparison of Infant Complication between Emergency and Caesarean Section

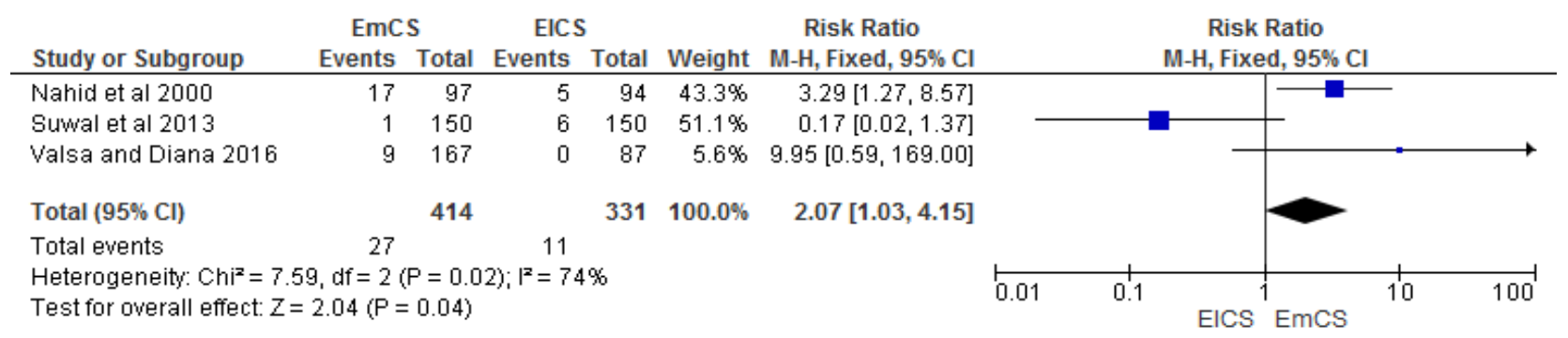

Figure 3. Forest plot Apgar score $<6$

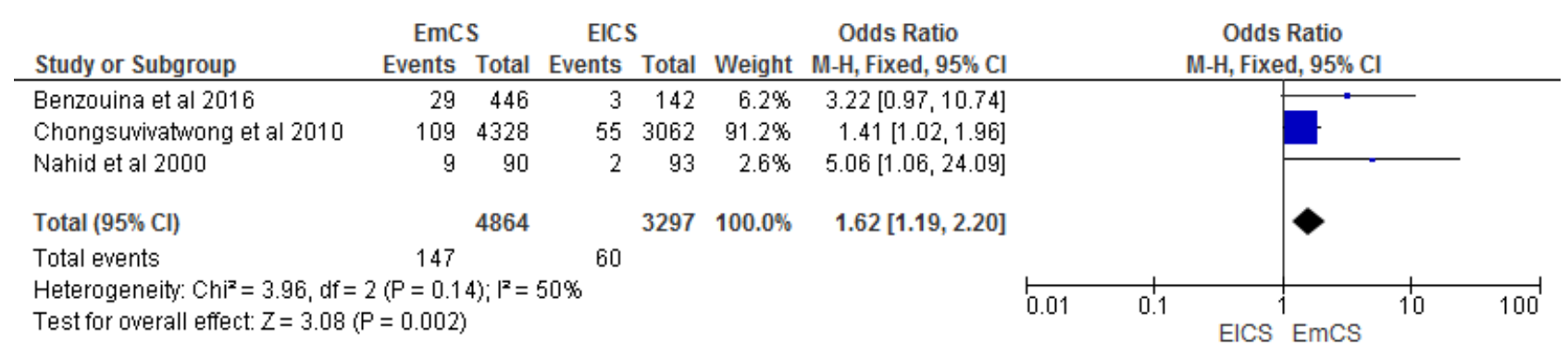

Figure 4. Forest plot hypoxia

\section{DISCUSSION}

The rate of caesarean section has increased dramatically, so that the complication rate has reached 50 to $70 \%$ in the last few decades (Yang and Sun, 2017). This study has proven that emergency caesarean section can increase complications in the fetus compared to elective caesarean section.

These results can be attributed to longer physical, mental and medical preparation, better obstetrician's surgical preparation, and also the condition of pregnant women in the ElCS process.

EmCS indications usually appear suddenly and are critical, so the baby's status is initially bad, so it is not surprising that more complications and may occur (Yang and Sun, 2017).

Previous research also explained the possibility of an increased risk of complications in EmCS because ElCS might be more commonly done in hospitals in urban areas with far better facilities (Sowmya et al., 2015).

Differences in Apgar scores have also been reported by (Gasparovic, 2006; Diana and Tipandjan, 2016; Najam 2013) which states that newborns in groups with elective caesarean section have a much better Apgar index score in the first minute $(\mathrm{p}=0.001)$ and in the fifth minute compared to children born in a group with emergency cesarean section. Children in the elective cesarean section were less frequent asphyxia and resuscitation were much less frequent than children in the group with emergency cesarean section $(p=0.014)$.

Emergency caesarean section is considered as a life-saving obstetric procedure and patients who have an indication for this procedure are at risk compared to elective caesarean section and vaginal delivery so they are prone to experience higher complication (Chongsuvivatwong et al., 2010).

The elective caesarean section is usually performed under controlled conditions and is better prepared, so the rate of tendency for complications will be lower than in an emergency situation (Govind et al, 2018).

EmCS patients come to the hospital after a failed attempt at home delivery and complications will arise. In some cases, the 
fetal head has reached the pelvic floor, this poses an extra challenge for obstetricians in conducting surgery (Onankpa and Ekele, 2009).

\section{AUTHOR CONTRIBUTION}

Rahmi Padlilah and Ika Yulianti collected and selected the articles, systematically reviewed the articles, ran meta-analysis, and wrote the manuscript.

\section{CONFLICT OF INTEREST}

We declared that there was no conflict of interest.

\section{FUNDING AND SPONSORSHIP}

There was no external funding.

\section{ACKNOWLEDGEMENT}

We give the best gratitude to the electronic database providers of PubMed, Science Direct, Web of Science, Springer Link and Cochrane Database.

\section{REFERENCE}

Benzouina S, Boubkraoui Mel-M, Mrabet M, Chahid N, Kharbach A, El-Hassani A, Barkat A (2016). Fetal outcome in emergency versus elective cesarean sections at Souissi Maternity Hospital, Rabat, Morocco. Pan Afr Med J, 23: 197. https://doi.org/10.11604/pamj.2016.23.197.7401.

Biondi-Zoccai G, Lotrionte M, Landoni G, Modena MG (2011). The rough guide to systematic reviews and meta-analyses. HSR proceedings in intensive care \& cardiovascular anesthesia. 3(3): 161-73. https://www.ncbi.nlm.nih.gov/pmc/articles/PMC3484632/

Govind L, Rajesh KV (2018). Obstetric outcome in elective vs emergency caesarean section. Indian $\mathrm{J}$ Med Res. 7(3): 5-6. https://doi.org/10.36106/paripex
Chongsuvivatwong V, Bachtiar H, Chowdhury ME, Fernando S, Suwanrath C, Kor-Anantakul O, Tuan le A, Lim A, et al. (2010). Maternal and fetal mortality and complications associated with cesarean section deliveries in teaching hospitals in Asia. J Obstet Gynaecol Res, 36(1): 45-51. https://doi.org/10$.1111 / \mathrm{j} .1447-0756.2009 .01100 . x$.

Diana V, Tipandjan A (2016). Emergency and elective caesarean sections: comparison of maternal and fetal outcomes in a suburban tertiary care hospital in Puducherry. International Journal of Reproduction, Contraception, Obstetrics and Gynecology, 5(9): 3060-3065. https://doi.org/10.18203/2320-1770.ijrcog20162985.

Gasparovic, Klepac-Pulanić T, Peter B (2006). Maternal and fetal outcome in elective versus emergency caesarean section in a developing country. Coll. Antropol. 30(30): 113-118.

Lucas DN, Yentis SM, Kinsella SM, Holdcroft A, May AE, Wee M, Robinson PN (2000). Urgency of caesarean section: a new classification. J Roy Soc Med. 93(7): 346-50. https://dx.doi.org/10.1177\%2Fo14107680009300703

Najam R, Sharma R (2013). Maternal and fetal outcomes in elective and emergency caesarean sections at a teaching hospital in North India. A retrospective study. J Adv Res Biolo Sci 5: 5-9

National Institute for Health and Care Excellence [NICE] (2011). Caesarean section. (Quality standard [QS32]).

Onankpa B, Ekele B (2009). Fetal outcome following cesarean section in a University Teaching Hospital. J Natl Med Assoc. Elsevier Masson SAS, 101(6): 578-581. https://doi.org/10.1016/So027-9684(15): 30943-3.

Sowmya M, Shashidhar S, Vijayalakshmi S 
(2015). A comparative study of outcome of caesarean delivery in rural obstetric referrals with elective caesarean delivery. Int $J$ Gynaecol Obstet.

Thakur V, Chiheriya H, Thakur A et al (2015) Study of maternal and fetal outcome in elective and emergency caesarean section. Int J Med Res Rev. 3: 1300-1305. https://doi.org/10.17511/ijmrr.2015.i11.236

Vogel JP, Betrán AP, Vindevoghel N, Souza JP, Torloni MR, Zhang J, Tunçalp Ö, Mori R et al. (2015). Use of the Robson classification to assess caesarean section trends in 21 countries: A secondary analysis of two WHO multicountry surveys. Lancet Glob Health.
https://doi.org/10.1016/S2214-109X(15)70094-X.

World Health Organization (2015). WHO recommendations on health promotion interventions for maternal and newborn health. World Health Organization Offset Publication. https://doi.org/10.1017/CBO9781107415324.004 .

Yang XJ, Sun SS (2017). Comparison of maternal and fetal complications in elective and emergency cesarean section: A systematic review and metaanalysis. Archives of Gynecology and Obstetrics. Springer Berlin Heidelberg, 296(3): 503-512. https://doi.org/10.1007/s00404-017-4445-2. 